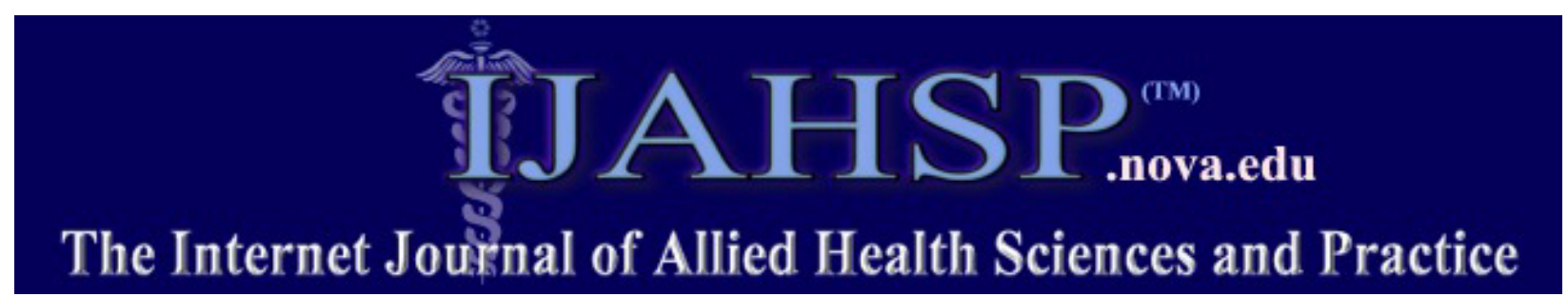

A Peer Reviewed Publication of the College of Health Care Sciences at Nova Southeastern University

Dedicated to allied health professional practice and education

http://ijahsp.nova.edu Vol. 10 No. 3 ISSN 1540-580X

\title{
Effect of Treadmill Training on Gait and Functional Independence in Patients with Incomplete Spinal Cord Injury: A Case Series
}

\author{
Shahnawaz Anwer, MPT ${ }^{1}$ \\ Ameed Equebal, MD2 \\ Ratnesh Kumar, MS, DNB ${ }^{3}$
}

1. Physiotherapist, National Institute for the Orthopaedically Handicapped, Bonhooghly, Kolkata

2. Assistant Director, National Institute for the Orthopaedically Handicapped, Bonhooghly, Kolkata

3. Director, National Institute for the Orthopaedically Handicapped, Bonhooghly, Kolkata

India

CITATION: Anwer S, Equebal A, Kumar R. Effect of Treadmill Training on Gait and Functional Independence in Patients with Incomplete Spinal Cord Injury: A Case Series. The Internet Journal of Allied Health Sciences and Practice. July 2012. Volume 10 Number 3.

\begin{abstract}
Background and purpose: Many individuals with an incomplete spinal cord injury (SCl) have the potential to walk. The effectiveness of using a treadmill for gait training for these patients has been substantiated in the literature. This case series describes the effectiveness of incorporating gait training on a treadmill for two individuals with an incomplete SCl. Case Description: The treatments of two males each with an incomplete paraplegia were described. Subject 1 was 40 years old and was 14 months post injury at the time of the study. He had a T6 incomplete spinal cord injury classified as a D on the American Spinal Injury Association (ASIA) Impairment Scale and neurological classification standards. Subject 2 was 48 years old and was 10 months post injury. He had a T8 incomplete spinal cord injury classified as ASIA C. Intervention: Both subjects participated in gait training for a maximum of 10 minutes on a motorized treadmill without elevation at a comfortable walking speed three days a week for four weeks as an adjunct to a conventional physiotherapy programme. Results: An increase in step length, stride length, cadence, and comfortable walking speed were noted in both subjects. Both subjects improved their walking level as measured by the Walking Index for Spinal Cord Injury (WISCI II) and functional independence as measured by Spinal Cord Independent Measure (SCIM II). Conclusion: Gait training on a treadmill can improve gait parameters and functional independence in patients with incomplete paraplegia. Further research is needed to improve the generalizability of these findings and to identify which patients might benefit most from treadmill training.
\end{abstract}

\section{INTRODUCTION}

Ambulation is a prime concern for individuals who have sustained a spinal cord injury. Many individuals with an incomplete spinal cord injury $(\mathrm{SCl})$ have the potential to walk. The effectiveness of using a treadmill for gait training for individuals who have sustained an incomplete $\mathrm{SCl}$ has been established over the last few years. ${ }^{1-3}$ It is theorized that the spinal cord has its own locomotion pattern generators that can induce basic gait motion patterns when being provided with the necessary sensory input. These pattern generators can be activated even if there is no voluntary control of motor segments such as in a complete cervical lesion of the spinal cord. 4,5

Wernig et al. demonstrated that in acute, incomplete $\mathrm{SCl}$, treadmill training enabled patients who were dependent on a wheelchair for mobility to become ambulatory compared to those who only received conventional methods of treatment alone. ${ }^{6}$

(c) The Internet Journal of Allied Health Sciences and Practice, 2012 
However, Dobkin et al., while comparing the effectiveness of body weight-supported treadmill training (BWSTT) with a control group who participated in gait training using an over-ground mobility programme with parallel bars or braces, found no significant difference between the two training methods in patients with grade $C$ or D on the American Spinal Injury Association (ASIA) Impairment Scale.7 Further, both groups showed improvements. This study suggested that it is not the type of training used but rather the targets and parameters that are set that are beneficial. This case series describes the incorporation of gait training on a treadmill as a valuable training adjunct for ambulatory patients with incomplete $\mathrm{SCl}$.

\section{CASE DESCRIPTION}

Two males with incomplete paraplegia received gait training on a treadmill as an adjunct to their conventional physiotherapy programmes. Subject 1 was 40 years old and was 14 months post injury at the time of the study. He had a T6 incomplete spinal cord injury classified as a D on the American Spinal Injury Association (ASIA) Impairment Scale and neurological classification standards. Subject 2 was 48 years old and was 10 months post injury. He had a T8 incomplete spinal cord injury classified as ASIA C on the American Spinal Injury Association (ASIA) Impairment Scale. Both subjects were able to walk on level ground with the use of a standard walker or two crutches. Prior to participation in the study, both subjects signed an informed consent form approved by the institutional ethical committee.

\section{TRAINING PROCEDURE}

Both subjects participated in gait training for a maximum of 10 minutes on a motorized treadmill without elevation at a comfortable self-selected walking speed three days a week for four weeks as an adjunct to their conventional physiotherapy programmes. Speed was gradually increased from $0.5 \mathrm{~m} / \mathrm{sec}$ to $3 \mathrm{~m} / \mathrm{sec}$ according to the patient's ability, while the subjects held onto the handrail for support. Gait speeds during treadmill training were chosen well below over-ground walking velocities of the patients to permit for gait corrections and longer training sessions without interruption. The therapist provided the subjects with verbal cues for taking equal step lengths and for sustaining an upright posture to maintain balance.

The subjects' conventional physiotherapy included stretching exercises for tight lower extremity musculature such as the hamstrings, adductors, iliopsoas, and gastrosoleus. Each stretch was performed for three repetitions with a 30-second hold, followed by a minimum of 30 minutes of standing in the Oswestry frame. Subjects then participated in mat activities including kneel standing, kneel walking, push ups, bridging, and abdominal curls for 30 minutes.

Subjects also participated in a strengthening programme for upper extremities and balance training. Strengthening exercises for the upper extremity muscles such as shoulder abductors, adductors, rotators, biceps brachii, and triceps brachii were completed for 3 sets of 10 repetitions each following the Delorme regimen of progressive resistive exercise (PRE). ${ }^{8}$ The rest period between repetitions and sets was 30 seconds and 60 seconds respectively and 5 minutes between exercises. Increases of $10 \%$ resistance were made gradually every week. ${ }^{8}$

Balance training consisted of task oriented training on a physio ball. While sitting on the physio ball, each subject reached forward, to the left and to the right, while trying to touch the therapist's hand. Only when the subject could actually touch the therapist's hand were they marked "task completed." For forward reach, both hands of subjects were extended. For the left and right side reach, reaching from one side to the other was counted as one repetition. Each task was performed in sets of 5 , consisting of 10 repetitions, with a one minute rest between each set.

\section{OUTCOME MEASURES}

The gait parameters, walking capability, and functional independence of the subjects were used as the outcome measures for this study. Gait parameters assessed included step length, stride length, cadence, and comfortable walking speed (CWS).

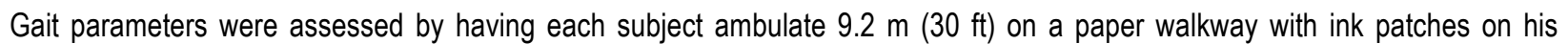
shoes, which left behind a footprint. Gait time for $6.1 \mathrm{~m}(20 \mathrm{ft})$ was recorded with a digital stopwatch. The first and last $1.5 \mathrm{~m}(5 \mathrm{ft})$ of the trial was not used because of changes in velocity that occur when a person starts/stops walking. Each subject completed a practice trial-walk (no ink) followed by a five minute rest period. The subjects then completed the trial with ink. ${ }^{9}$ Measurements were taken using a measuring scale and markers. Stride length was measured as the distance between two successive foot prints of the same foot. Step length was measured as the distance between two successive foot prints, right to left heel and left to right heel. Cadence was determined by the number of steps taken during the measured gait time and recorded as steps per minute. CWS, defined as self-selected comfortable cadence, was calculated in centimetres per second as follows: $\mathrm{CWS}(\mathrm{cm})=$ Step length $\mathrm{x}$ cadence/60. 
Walking capability was assessed using the Walking Index for Spinal Cord Injury (WISCI II) while functional independence was measured using the Spinal Cord Independence Measure (SCIM II). Both scales are reliable and valid.10,11 The WISCI II categorizes a person's walking capability based on the need for physical assistance and assistive devices and/or braces. ${ }^{12}$ It is a 20 -item scale with a range of 20 in which a score of 0 means the patient is unable to walk and a score of 20 means the patient can walk with no assistive device, no braces, and no assistance for at least 10 meters. ${ }^{13}$

The Spinal Cord Independence Measure (SCIM II) is a disability scale used to assess the capacity of the individuals to perform daily tasks. It consists of 16 individual tasks (items) divided into three subscales (areas of function), as follows: self-care (score range 0 to 20), respiration and sphincter management (0 to 40), and mobility (0 to 40). Mobility is scored separately for room/toilet and indoors/outdoors. The total score ranges between 0 and 100, with higher scores meaning that a person is more independent. ${ }^{11}$

\section{RESULTS}

Both subjects demonstrated improvements in their gait parameters, walking level, and functional independence over the four week training periods. Table 1 details the outcomes of training for each subject.

Table 1. Comparison of Gait Parameters, Walking Level, and Functional Independence

\begin{tabular}{|c|c|c|c|c|}
\hline Variables & \multicolumn{2}{|c|}{ Subject 1 } & \multicolumn{2}{c|}{ Subject 2 } \\
\hline & Baseline & Week 4 & Baseline & Week 4 \\
\hline Step length (cm) & 24 & 42 & 20 & 34 \\
\hline Stride length (cm) & 54 & 86 & 42 & 70 \\
\hline Cadence (steps/min) & 84 & 106 & 72 & 90 \\
\hline CWS (cm/sec) & 33.6 & 74.2 & 24 & 51 \\
\hline WISCl & 8 & 19 & 12 & 19 \\
\hline SCIM & 59 & 97 & 44 & 88 \\
\hline
\end{tabular}

\section{DISCUSSION}

These case studies examined the effects of treadmill training on gait and functional independence in two patients with an incomplete SCl. Gait training on a treadmill following an incomplete SCl helps reorganize the spinal cord connections and uses the spinal cord's plasticity and memory to re-learn locomotor pattern. ${ }^{14}$ Treadmill training also influences the electrophysiological properties of motor neurons, decreasing the after-hyperpolarization phase which correlates with recovery of locomotion function. This is most likely a result of the greater ability of the motor neurons to achieve doublet firing providing enough force to achieve locomotion. ${ }^{15}$ Previous studies recognize gait training as a promising strategy for enhancing locomotor recovery in adults with an incomplete $\mathrm{SCl} .{ }^{6}$ The results of this case series also suggest that treadmill training without weight support is feasible and beneficial for patients with incomplete paraplegia.

Behrman et al. reported that after treadmill training, a subject with a chronic, incomplete $\mathrm{SCl}$, who prior to training ambulated only short distances within the home using a rolling walker, ambulated full-time using forearm crutches. ${ }^{16}$ Nooijen et al. demonstrated significant improvements in cadence, step length, and stride length after locomotor training in individuals with chronic SCl.17 This is further supported by Field-Fote et al. who reported improved walking speed with both over-ground training and treadmill-based training in people with chronic motor incomplete SCl. ${ }^{18}$ However, walking distance improved to a greater extent with over-ground training.

Conversely, a study by Wirz et al. showed that only 2/20 patients with ASIA C or D grades demonstrated improvements in walking ability, as determined by WISCI II scores. ${ }^{19}$ One subject who used 2 crutches before the training series could walk with only 1 cane after training but still required a leg brace (WISCI II score increased from 12 to 15). Another subject used a single straight cane before training and did not need an assistive device after 8 weeks of locomotor therapy (WISCI II score change from 19 to 20). Patients who were non-ambulatory before the study did not regain locomotor ability. However, all patients improved their walking speed and endurance while being supported on a treadmill.

In previous studies, training duration was reported to be 15 minutes, 20 minutes, or 30 minutes at a frequency of 3 days a week or 5 days a week. $4,16,17,20,21$ However; we chose a less intensive training protocol consisting of 10 minutes at a frequency of 3 days a week for 4 weeks because patients received treadmill training without body weight support.

We presented the results of two individual case studies. Without a control group, factors other than the locomotor training such as age, severity, level, and chronicity of injury may have contributed to the outcomes and affected the recovery of locomotion. 
Therefore, investigating the influence of these factors on the outcomes of locomotor training is certainly warranted via controlled, experimental studies. To our knowledge, this is the only published case study of locomotor training on a treadmill in which body weight support is not provided. Therefore, direct comparisons must be made in individuals with chronic $\mathrm{SCl}$ before definitive conclusions can be reached.

\section{CONCLUSIONS}

In these 2 case studies, gait training on a treadmill improved the ambulation ability and functional independence in individuals with incomplete $\mathrm{SCl}$. Further research is needed to improve the generalizability of these findings and to identify which patients might benefit most from treadmill training.

\section{REFERENCES}

1. Abel R, Schablowski M, Rupp R, Gerner HJ. Gait analysis on the treadmill - monitoring exercise in the treatment of paraplegia. Spinal Cord. 2002;40(1):17-22. [PMID 11821965]

2. Burns SP, Golding DG, Rolle WA Jr, Graziani V, Ditunno JF Jr. Recovery of ambulation in motor-incomplete tetraplegia. Arch Phys Med Rehabil. 1997;78(11):1169-72. [PMID 9365343]

3. Hicks AL, Adams MM, Martin Ginis K, Giangregorio L, Latimer A, Phillips SM, McCartney N. Long-term body-weightsupported treadmill training and subsequent follow-up in persons with chronic $\mathrm{SCl}$ : effects on functional walking ability and measures of subjective well-being. Spinal Cord. 2005;43(5):291-8. [PMID 15685260]

4. Dietz V, Harkema SJ. Locomotor activity in spinal cord-injured persons. J Appl Physiol. 2004;96(5):1954-60. [PMID 15075315]

5. Nicol DJ, Granat MH, Baxendale RH, Tuson SJ. Evidence for a human spinal stepping generator. Brain Res. 1995;684(2): 230-2. [PMID 7583229]

6. Wernig A, Muller S, Nanassy A, Cagol E. Laufband therapy based on 'rules of spinal locomotion' is effective in spinal cord injured persons. Eur J Neurosci. 1995;7(4):823-9. [7620630]

7. Dobkin B, Apple D, Barbeau H, Basso M, Behrman A, Deforge D, et al. Weight-supported treadmill vs over-ground training for walking after acute incomplete SCI. Neurology. 2006;66(4):484-93. [16505299]

8. Fish DE, Kraback BJ, Johnson-Greene D, Delateur BJ. Optimal resistance training: comparison of DeLorme with Oxford techniques. Am J Phys Med and Rehabil. 2003;82(12):903-9. [14627926]

9. Holden MK, Gill KM, Magliozzi MR, Nathan J, Piehl-Baker L. Clinical Gait Assessment in the Neurologically Impaired: Reliability and Meaningfulness. Phys Ther. 1984;64(1):35-40. [PMID 6691052]

10. Marino RJ, Scivoletto G, Patrick M, Tamburella F, Read MS, Burns AS, Hauck W, Ditunno J. Walking Index for Spinal Cord Injury version 2 (WISCl-II) with repeatability of the 10-m walk time; Inter- and intrarater reliabilities. Am J Phys Med Rehabil. 2010;89(1):7-15. [PMID 20026943]

11. Itzkovich M, Tripolski M, Zeilig G, Ring H, Rosentul N, Ronen J, et al. Rasch analysis of the Catz-Itzkovich spinal cord independence measure. Spinal Cord. 2002;40(8):396-407. [12124666]

12. Dittuno PL, Dittuno JF Jr. Walking index for spinal cord injury (WISCI II): scale revision. Spinal Cord. 2001;39(12):654-6. [11781863]

13. Morganti B, Scivoletto G, Dittuno PL, Ditunno JF, Molinari M. Walking Index for Spinal Cord Injury (WISCI): criterion validation. Spinal Cord. 2005;43(1):27-33. [PMID 15520841]

14. Cote MP, Menard A, Gossard JP. Spinal cats on the treadmill: changes in load pathways. J Neurosci. 2003;23(7): 2789-96. [PMID 12684465]

15. Petruska JC, Ichiyama RM, Jindrich DL, Crown ED, Tansey KE, Roy RR, et al. Changes in motoneuron properties and synaptic inputs related to step training after spinal cord transaction in rats. J Neurosci. 2007;27(16):4460-71. [PMID 17442831]

16. Behrman AL, Lawless-Dixon AR, Davis SB, Bowden MG, Nair P, Phadke C, et al. Locomotor training progression and outcomes after incomplete spinal cord injury. Phys Ther. 2005;85(12):1356-71. [PMID 16305274]

17. Nooijen CF, Ter Hoeve N, Field-Fote EC. Gait quality is improved by locomotor training in individuals with $\mathrm{SCl}$ regardless of training approach. J Neuroeng Rehabil. 2009;6:36. doi:10.1186/1743-0003-6-36. [PMID 19799783]

18. Field-Fote EC, Roach KE. Influence of a locomotor training approach on walking speed and distance in people with chronic spinal cord injury: a randomized clinical trial. Phys Ther. 2011;91(1):48-60. [PMID 21051593]

19. Wirz M, Zemon DH, Rupp R, Scheel A Colombo G, Dietz V, Hornby TG. Effectiveness of automated locomotor training in patients with chronic incomplete spinal cord injury: a multicenter trial. Arch Phys Med Rehabil. 2005;86(4):672-80. [PMID 15827916]

20. Wirz M, Colombo G, Dietz V. Long term effects of locomotor training in spinal humans. J Neurol Neurosurg Psychiatry. 2001;71(1):93-6. [PMID 11413270] 
21. Gardner MB, Holden MK, Leikauskas JM, Richard RL. Partial body weight support with treadmill locomotion to improve gait after incomplete spinal cord injury: a single-subject experimental design. Phys Ther. 1998;78(4):361-74. [PMID 9555919]

\section{KEY TERMS}

Gait Training, Spinal Cord Injury, Paraplegia, Treadmill Training 